\title{
Evaluation of the Impacts of Regional Climate Factors and Crop Management on Corn Yields in Different Climate Regimes of China Using the DayCent Model
}

\author{
Aihong $\mathrm{Fu}^{1,2}$, Yongkang Xue ${ }^{3}$, Melannie D. Hartman ${ }^{4}$, Weihong $\mathrm{Li}^{1}$, Bo Qiu ${ }^{3}$, Ye Liu ${ }^{3}$, Y. N. Chen ${ }^{1} \&$ Y. Wang ${ }^{1}$ \\ ${ }^{1}$ State Key Laboratory of Desert and Oasis Ecology, Xinjiang Institute of Ecology and Geography, Chinese \\ Academy of Science, Urumqi, Xinjiang, China \\ ${ }^{2}$ University of Chinese Academy of Sciences, Beijing, China \\ ${ }^{3}$ Department of Geography, University of California, Los Angeles, CA, USA \\ ${ }^{4}$ Natural Resource Ecology Laboratory, Colorado State University, Fort Collins, CO, USA \\ Correspondence: Aihong Fu, State Key Laboratory of Desert and Oasis Ecology, Xinjiang Institute of Ecology \\ and Geography, Chinese Academy of Sciences, Urumqi, Xinjiang 830011, China. Tel: 86-991-782-3173. E-mail: \\ fuah@ms.xjb.ac.cn
}

Received: June 18, 2019

Accepted: July 25, 2019 Online Published: September 15, 2019

doi:10.5539/jas.v11n15p35

URL: https://doi.org/10.5539/jas.v11n15p35

\begin{abstract}
Corn is one of most important agricultural products in China. Understanding impacts of regional climate change, as well as agricultural management practices, on corn yields is critical for maintaining stable corn production. Using the DayCent model and observed climatic data in Sichuan province (a humid and hot environment) and Hebei province (a cold and dry environment) in China, corn yields in 1948-2010 were simulated. The spatial variations of simulated corn yields and the relationship between regional climate variability and warming with corn yields in these two environments were analyzed. The results demonstrated that: (1) corn yields in Zhangjiakou of Hebei and most regions of Sichuan decreased significantly after 2000 compared to other regions; (2) relative humidity and precipitation exhibit a significant negative correlation with observed crop yields in the growing season in Hebei province; (3) air temperature from $23.33{ }^{\circ} \mathrm{C}$ to $29{ }^{\circ} \mathrm{C}$ constitutes the ideal range influencing the increase of corn yields in Sichuan; (4) the planting of the large amount of silage maize in Sichuan compensated the negative impact of the rising air temperature on corn yields; (5) sensitivity tests for different fertilization levels and OMAD suggest that an increasing fertilization level significantly affects corn yields in Hebei province, a cold and dry environment, while a decreasing fertilization level has a significant negative effect in Sichuan province, a hot and humid environment. The overarching goal of these analyses is to provide the theoretical basic for maintaining stable corn production under regional climate warming and different agricultural management practices.
\end{abstract}

Keywords: corn yields, DayCent model, climate variability and change, fertilization level, organic matter additions

\section{Introduction}

Corn is one of the most important crops globally, and its production has increased continuously from 2008 to 2015 in China, reaching 22 trillion $\mathrm{kg}$ in 2016. This increase of corn production has been attributed to enlargement of cultivated areas and advancements in production technology (B. Chen \& G. Chen, 2007; Peng, Tang, \& Zou, 2009; Yu, Huang, \& Zhang, 2012; Bryan, King, \& Zhao, 2014; Nendel, Kersebaum, Mirschel, \& Wenkel, 2014). Effects of climate factors on corn yields have also been widely studied. Some extant literature has investigated the effect of air temperature (Wolfram \& Michael, 2009; Yin et al., 2016; Lobell \& Field, 2007; Basche et al., 2016; S. Chen, X. G. Chen, \& J. T. Xu, 2016; Lee \& Durmaz, 2016; Meng, Carew, Florkowski, \& Klepacka, 2016), while others have focused on the effect of other climatic factors, such as precipitation and wind (Yin et al., 2016; Lee \& Durmaz, 2016; Wang, Bocoling, \& Cherkauer, 2016). A number of studies found that rising air temperature in the growing season, especially in July or in the seeding and maturity phases, increased corn yields (Wolfram \& Michael, 2009; Yin et al., 2016). However, scholars have also reported that climate change has resulted in the reduction of corn yield over several countries in the past few decades (Wolfram \& 
Michael, 2009; Lobell \& Field, 2007; Basche et al., 2016; S. Chen, X. G. Chen, \& J. T. Xu, 2016; Lee \& Durmaz, 2016; Almarza, Mabood, Zhou, Gregorich, \& Smith, 2008). In fact, Chen et al. (2016) reported that corn yield is projected to decline by $3-12 \%$ by 2100 in China due to rising air temperature. In the U.S., it was found that after the average growing-season air temperature exceeded $29^{\circ} \mathrm{C}$, corn yield would decrease sharply (Wolfram \& Michael, 2009). Warming since 1981 has resulted in annual combined losses of crops representing roughly $40 \mathrm{Mt}$ or USD $\$ 5$ billion per year, as of 2002 (Lobell \& Field, 2007). A 1\% increase in the growing season air temperature reduces corn yield per acre by $9 \%$ (Lee \& Durmaz, 2016). Increases in minimum and maximum air temperatures were attributed to reduced yields of $1.6-2.7 \%$ by decade (Basche et al., 2016). Although different climate characteristics among the study areas explain some temperature responses in corn yields, there is a general lack of comprehensive research on the effect of air temperature on crop yield. In this study, we thoroughly investigate this issue by studying the relationship between air temperature and corn growth in two different regions in China.

To analyze the impact of climate on corn yield, various models have been utilized, such as empirical frameworks (S. Chen, X. G. Chen, \& J. T. Xu, 2016), regression models (Wolfram \& Michael, 2009), statistical models (Basche et al., 2016; Almarza, Mabood, Zhou, Gregorich, \& Smith, 2008), climatic models (IHadRM3, C4I, REMO-MPI, ETHZ, CNRM, DMI-HIRHAM, KNMI, SMHI) (Voloudakis et al., 2015), the Agricultural Production Systems sIMulator (APSIM) (Basche et al., 2016), crop simulation models (Morell et al., 2016), and crop growth models (Silva, Reidsma, Laborte, \& van Ittersum, 2017). These approaches possess respective strengths and weaknesses. For example, although the DNDC model considers the cropping system, fertilizer and straw return in its crop simulations, it only employs a few key management practices (Morell et al., 2016). A crop growth model (ORYZA v3) was able to simulate rice yield relatively well, but tended to overestimate other crops' yields (Silva, Reidsma, Laborte, \& van Ittersum, 2017). APSIM and HERMES address the agricultural management practice factor in analyzing the impact of climate change on corn yield, but only limited numbers of management factors were considered. In this study, we employ the DayCent model (Parton, Hartman, Ojima, \& Schimel, 1998; Parton et al., 2001) to test the effects of key climatic factors, warming air temperatures, and various agricultural management practices on crop yield.

DayCent is a process-based biogeochemical model, and is a useful tool to predict yields as it integrates crop growth, carbon and nutrient dynamics, hydrology, management, and climate. Many studies have utilized DayCent to simulate changes in soil C, soil N, and greenhouse gas emissions (Wieder, Bonan, \& Allison, 2014; Sheehan et al., 2013; Frey, Lee, Melillo, \& Six, 2015; Cheng, Ogle, Parton, \& Pan, 2014; Robertson, Grace, Izaurralde, Parton, \& Zhang, 2014; Rafique, Fieneu, Parkin, \& Anex, 2013; Reay et al., 2012; Mangalassery et al., 2014). Only a few previous studies have examined grain yield change under different climatic conditions and agricultural management practices using this model in China (Campbell et al., 2014; Lee, De, \& Six, 2011). Cheng et al. (2014) used the DayCent model to successfully simulate crop yields in China, but focused on analyzing greenhouse gas mitigation potential and not the response of crop yields to future climatic change. In this study, variability in corn yields within each study region and the response to future climatic change were analyzed.

We selected Hebei province (a dry and cold environment) and Sichuan province (a warm and humid environment) in China as study areas, which possess quite different climate backgrounds (Figure 1). The spatial variation of simulated corn yields and the relationship between regional climate change, regional warming, and corn yield are reported in this study. The sensitivity of agricultural management practices in simulating corn yields by DayCent is also discussed. 


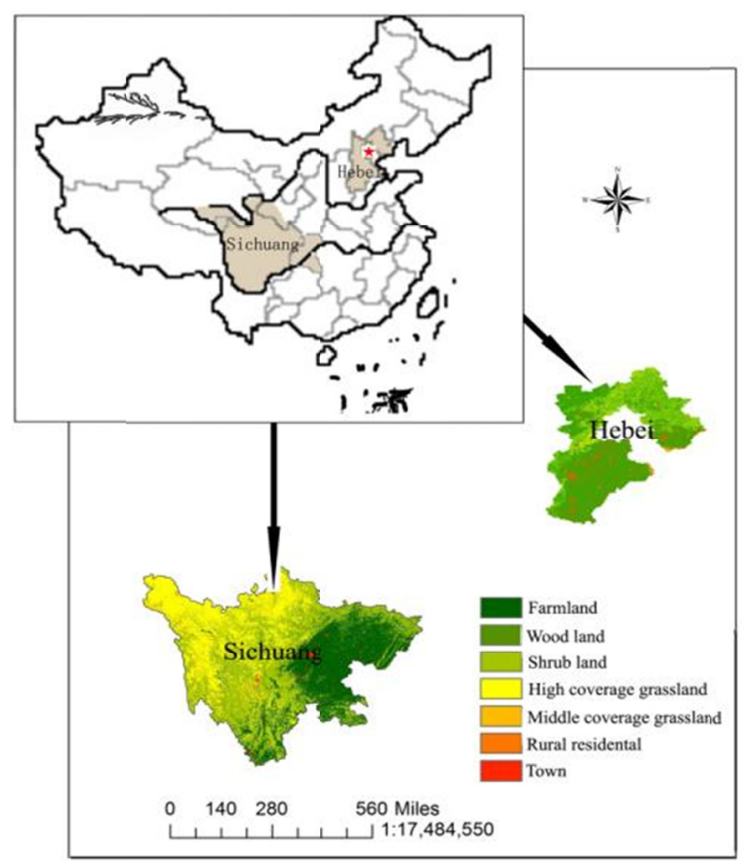

Figure 1. The geographic locations of the study area in China

\section{Methods}

\subsection{Study Area}

The geographic areas in this study, Hebei (E $113^{\circ} 04^{\prime}$ to $119^{\circ} 53^{\prime}, \mathrm{N} 36^{\circ} 01^{\prime}$ to $\left.42^{\circ} 37^{\prime}\right)$ and Sichuan (E97 $21^{\prime}$ to $108^{\circ} 33^{\prime}$, N26 $03^{\prime}$ to $34^{\circ} 19^{\prime}$ ) provinces in China are located in the northeast and southwest of China, respectively (Figure 1). Although they exhibit different climate characteristics, both have high corn acreage and production. Hebei has a temperate monsoon climate/warm temperate, humid-semi-arid continental monsoon climate, with an annual mean air temperature of $4-13{ }^{\circ} \mathrm{C}$ and an annual mean precipitation of $400-800 \mathrm{~mm} / \mathrm{yr}$ (based on 63 years (1948-2010) of data). Climate is characterized by cold winters with little snow, hot summers with substantial rainfall, and windy springs and autumns with less rainfall. Climate in Sichuan is characterized by warm winters, dry springs, hot summers, rainy autumns, substantial fog, and less sunshine in the east, and by cold and long winters, short summers, abundant sunshine, and concentrated rainfall in the west.

Hebei is located in northern China, with an area of 188 thousand $\mathrm{km}^{2}$. It encompasses 11 prefecture-level cities, 22 county-level cities, 108 counties, and six autonomous counties. The province's terrain slopes upward from the northwest to southeast. Hills, mountains and plateaus are in the northwest, with an average altitude of 1200-1500 $\mathrm{m}$; plains are in central and southeast China, with an average altitude of less than $50 \mathrm{~m}$.

Sichuan is located in the upper reaches of Changjiang River in southwest China, with an area of 99 thousand $\mathrm{km}^{2}$. It is covered by plateaus in the west and basins in the east. The terrain is higher in the west with an altitude of 4000-5000 $\mathrm{m}$, and lower in the east.

\subsection{Selection of Study Locations}

In Sichuan, we selected 18 counties (Figure 2a), including Abazhou, Bazhong, Chengdu, Dazhou, Deyang, Guangan, Guangyuan, Leshan, Xiaojin, Luzhou, Meishan, Mianyang, Nanchong, Neijiang, Yaan, Yibin, Zigong and Ziyang as study areas, which constitute the primary agricultural regions in the province. In Hebei, we selected 17 grid locations (Figure $2 \mathrm{~b}$ ) that were uniformly distributed within the boundary ranges of latitude and latitude covered by Hebei province and were not based on counties. This method ensured the broadest range of surface conditions and crop yields within the province, since conditions within individual counties are quite variable. Some locations in the boundary and out of the boundary were discarded because they were not representative of farmland. The latitude or longitude of the interval between adjacent two grid locations is $1^{\circ}$ and are marked with letters "a" to "q", respectively, in Figure $2 b$. 

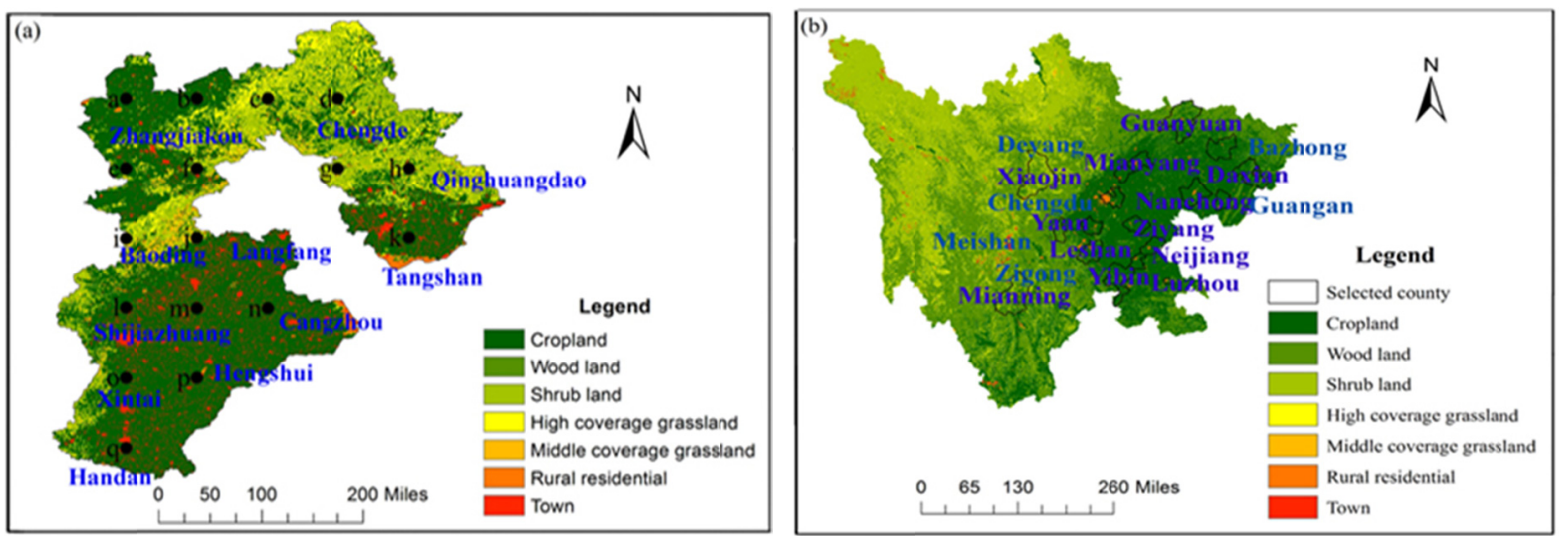

Figure 2. Land cover and selected locations in Hebei (a) and selected counties in Sichuan (b) in 2013. In selected locations of Hebei, a, b, c, e, and f represents Zhangjiakou. $\mathrm{d}$, g, and $\mathrm{h}$ represent Chengde. $\mathrm{k}$ represents Tangshan. $\mathrm{i}$ represents Baoding. $\mathrm{j}$ represents langfang. 1 and $\mathrm{m}$ represent Shijiazhuang. $\mathrm{n}$ represents Cangzhou. o represents Xintai. p represents Hengshui. q represents Handan

\subsection{DayCent Model}

DayCent is a daily time-step version of the Century model that simulates plant production, trace gas fluxes $\left(\mathrm{N}_{2} \mathrm{O}\right.$, $\mathrm{NOx}, \mathrm{CH}_{4}$ ), and the dynamics of carbon and nitrogen in grassland, forest, savanna, and agricultural systems (Wieder, Bonan, \& Allison, 2014; Sheehan et al., 2013; Frey, Lee, Melillo, \& Six, 2015; Cheng, Ogle, Parton, \& Pan, 2014; Robertson, Grace, Izaurralde, Parton, \& Zhang, 2014). The model has been widely utilized to simulate the impact of environmental changes (elevated $\mathrm{CO}_{2}$ and climatic changes, management practices) on production and yield in agro-ecosystems globally (Cheng et al., 2014; Robertson, Grace, Izaurralde, Parton, \& Zhang, 2014; Reay et al., 2012; Mangalassery et al., 2014).

\subsubsection{Model Inputs and Data Collection}

Model inputs are daily weather data, soil properties, and agricultural management practices (e.g., crop type, cultivation/planting schedules, amount and timing of nutrient amendments, irrigation, and tillage). The crop-specific parameter PRDX(1), a coefficient for calculating potential aboveground daily production as a function of solar radiation outside the atmosphere, is a critical important parameter. The values of PRDX(1) for the types of corn $(\mathrm{C} 1, \mathrm{C} 2, \mathrm{C} 3, \mathrm{C} 4, \mathrm{C} 5$, and $\mathrm{C} 6)$ increased in value according to the various corn productivity levels and were different for each province. This set of corn parameters for Hebei and Sichuan provinces was the same for all simulations, respectively. Measured corn yields from 1978 to 2010 were obtained from the Hebei Economic Year Book (2008-2011) and the Sichuan Statistical Year Book (2000-2011).

(1) Weather data: Daily weather data, which include daily maximum and minimum air temperature $\left(\mathrm{T}_{\min }\right.$ and $\mathrm{T}_{\max }$ ), daily precipitation (Prcp), daily solar radiation (Dswrf), daily relative humidity (RH), and daily wind speed (Wind), are necessary forces to drive ecosystem processes in DayCent. The weather data from 1948 to 2010 for this study were derived from the Princeton University Hydroclimatology Group Bias Corrected Meteorological Forcing Dataset (Sheffield, Goteti, \& Wood, 2006). The units of these data were converted according to the format required by DayCent.

(2) Soil data: Soil property data, specified by soil layer, comprised bulk density $\left(\mathrm{g} / \mathrm{cm}^{3}\right)$, field capacity, wilting point, evaporation coefficient, fraction of roots, fraction of sand and clay, saturated hydraulic conductivity, and $\mathrm{pH}$. All of these data were obtained by field survey and sample measurement in the study areas in 2016. Specifically, three plots of corn planted in 2016 in each county or location were selected in 18 counties of Sichuan province and 17 locations of Hebei province from August to September. Soil samples in each corn plot were collected using plastic bags. Fresh weight was determined at that time, and the samples were brought to the laboratory and dried at $105^{\circ} \mathrm{C}$. Dry weight was then obtained, and then soil water content was calculated.

(3) Crop management data: Agricultural management options, which are specified in the DayCent schedule file, include crop types, irrigation intensity, cultivation practices, residue removal during harvest, organic matter additions, inorganic fertilizer additions, and planting and harvest dates (Cheng et al., 2014). Corn growth in Hebei province is mainly dependent on irrigation, while corn growth in Sichuan province relies on irrigation and rainfall. Assuming ample water for irrigation, corn production is not limited by water availability in these two provinces. We define five periods according to production technology levels during the periods of 1948-2010 in 
China: 1948-1965, 1966-1975, 1976-1985, 1986-1995, and 1996-2010. The management options for these five periods were obtained through reports from local farmers and relevant literature (Liang, 2015; Liang et al., 2008; Luo et al., 2016; Liu et al., 1998; Chen, 2013).

\subsubsection{Evaluation Method}

Performance of the DayCent model was assessed using several quantitative methods (Janssen \& Heuberger, 1995). First, the main difference between the simulated and observed values was assessed by calculating the root mean square error (RMSE):

$$
\mathrm{RMSE}=\sqrt{\sum_{\mathrm{i}=1}^{\mathrm{n}}\left(\mathrm{S}_{\mathrm{i}}-\mathrm{O}_{\mathrm{i}}\right)^{2} / \mathrm{n}}
$$

where, $O_{i}$ and $S_{i}$ denote the observed and simulated values, respectively; and $n$ is the number of measurements. Second, the accuracy of the simulations was evaluated based on modeling efficiency (EF):

$$
\mathrm{EF}=\frac{\sum_{\mathrm{i}=1}^{\mathrm{n}}\left(\mathrm{O}_{\mathrm{i}}-\overline{\mathrm{O}}\right)^{2}-\sum_{\mathrm{i}=1}^{\mathrm{n}}\left(\mathrm{S}_{\mathrm{i}}-\mathrm{O}_{\mathrm{i}}\right)^{2}}{\sum_{\mathrm{i}=1}^{\mathrm{n}}\left(\mathrm{O}_{\mathrm{i}}-\overline{\mathrm{O}}\right)^{2}}
$$

where, $\bar{O}$ denotes the mean of the observed data; and $O_{i}$ and $S_{i}$ denote the observed and simulated values, respectively. A positive value of EF indicates good modeling efficiency, in which the closer the value is to +1 , the better is the modeling efficiency. Negative values of EF indicate poor modeling efficiency, in which the farther the value is from +1 , the worse is the modeling efficiency. Third, bias constitutes the main difference between the simulated and observed values, and was determined by calculating the relative error (E):

$$
\mathrm{E}=\frac{100}{\mathrm{n}} \sum_{\mathrm{i}=1}^{\mathrm{n}}\left(\mathrm{O}_{\mathrm{i}}-\mathrm{S}_{\mathrm{i}}\right)^{2} / \mathrm{O}_{\mathrm{i}}
$$

An $E$ value closer to 0 suggests a better model fit to the measurements. When both measurements and observations are positive numbers, a positive $E$ value indicates that the model underestimates the observations, and a negative $\mathrm{E}$ value indicates that it overestimates the observations.

We also analyzed the spatial variation and temporal correlation between simulated and observed corn yields from 1978-2010 by the Pearson correlation analysis method using SPSS 13.0 software.

\subsection{Factors that Affect Corn Yields and Experimental Designs}

Simulated corn yield was affected by numerous factors, including climate forcing and specified agricultural management practices. In this paper, we analyze the general relationship between climate variables and crop yields based on observation and model simulation. We also present the sensitivity of crop yields to management. Since we possessed no detailed information regarding crop management, we performed several sensitivity studies to test how each factor affects corn yield simulation. In the sensitivity tests, one factor at a time was changed (Figure 3 ). The sensitivity tests were designed as follows:

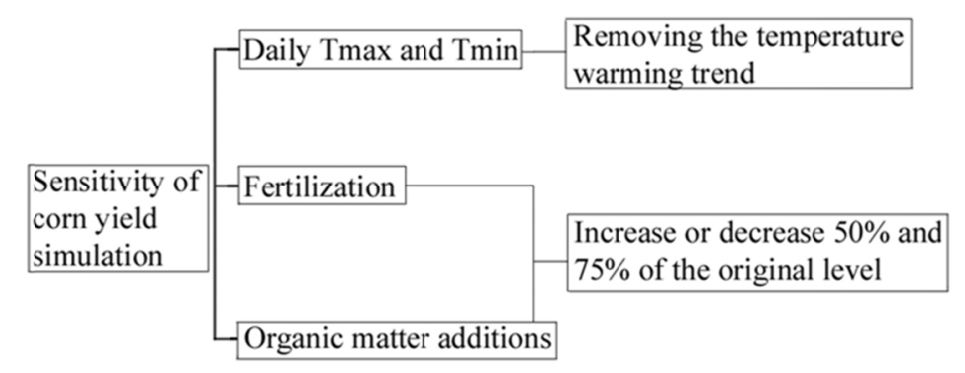

Figure 3. Schematic diagram of sensitivity analysis. (A) factors and (B) methods

(1) Sensitivity to air temperature. In the sensitivity study, we removed the trend of elevated air temperature from 1978 to 2010 in Hebei and Sichuan provinces (i.e., de-trending) by subtracting the annual mean values, which were derived from original daily $\mathrm{T}_{\max }$ and $\mathrm{T}_{\min }$. Comparisons between the actual and detrended mean growing season temperatures for each province are briefly presented in Figure 4. From Figure 4, it can be seen that the mean growing season $\mathrm{T}_{\max }$ in Hebei and Sichuan decreased by $0.08{ }^{\circ} \mathrm{C}$ and $0.43{ }^{\circ} \mathrm{C}$, respectively, after detrending; The mean growing season $\mathrm{T}_{\min }$ in Hebei and Sichuan decreased by $0.09^{\circ} \mathrm{C}$ and $0.44^{\circ} \mathrm{C}$, respectively, after detrending. All of these findings indicate that the mean growing season $\mathrm{T}_{\max }$ and $\mathrm{T}_{\min }$ in Hebei increased slightly in the past 23 years, but greatly in Sichuan. 
(2) Sensitivity to fertilizer and organic matter additions. Fertilizer management includes different fertilization timing and levels. In this paper, only fertilizer level was considered. The application of organic matter (OMAD) in the field after harvest maintains soil fertility for the following year. In the sensitivity tests, we added or decreased fertilization and OMAD level by $50 \%$ and $75 \%$ compared with the original setting. These fertilizer or OMAD amounts did not vary spatially in Hebei or Sichuan in this experiment. Organic matter (e.g., manure) is widely available in China so that applications can be increased (Zhao et al., 2017).

To assess sensitivity, we calculated the average simulated corn yields in the sensitivity simulation minus the average of the control simulated corn yields in the study period.
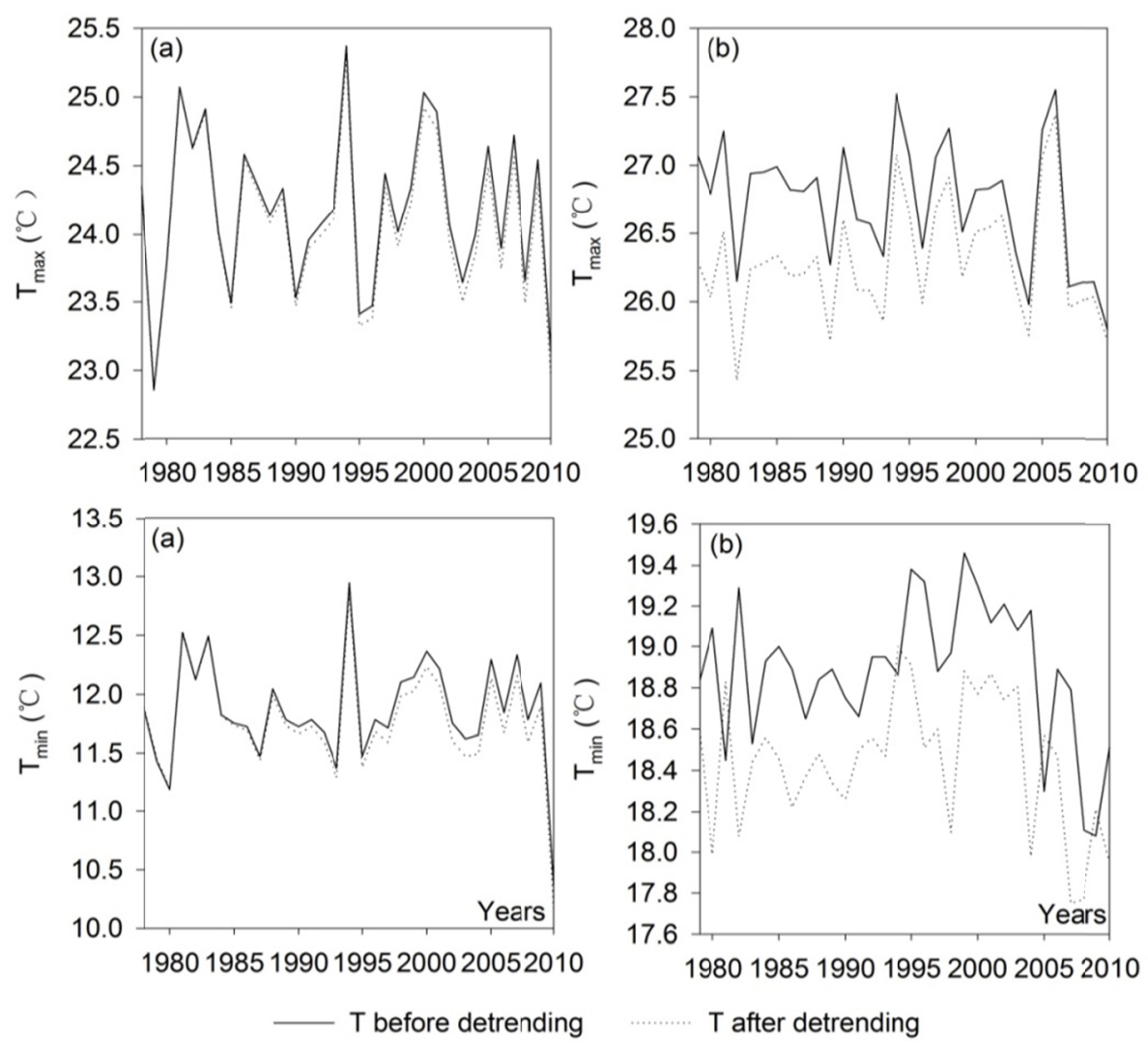

Figure 4. Change in mean growing season $\mathrm{T}_{\max }$ and $\mathrm{T}_{\min }$ before and after detrending in 1978-2010 in the province of (a) Hebei and (b) Sichuan

\subsection{Data Availability}

Weather data derived from the Princeton University Hydroclimatology Group Bias Corrected Meteorological Forcing Dataset. Soil data were obtained by field work in the study area. Crop management data were provided by the local farmers and Statistic Yearbook of the Sichuan and Hebei provinces.

\section{Results}

\subsection{Relationship Between Climate Variables and Corn Yields}

In this paper, corn yield only refers to grain yield, and does not include corn stalk. The simulated results are compared with measured corn yields for 1978-2010 (Figure 5). A strong correlation was found between mean simulated and observed corn yields, with $\mathrm{R}^{2}$ values of 0.842 in Hebei and 0.751 in Sichuan. These results are in agreement with Cheng et al. (2014), who also reported that the DayCent model was reasonably accurate in simulating crop yields with $\mathrm{R}^{2}$ values ranging from 0.71 to 0.85 in 350 cropland experiments in China. The values of RMSE, EF, and E are 875.12, -0.76, and 3.39 in Hebei, and 1173.28, -0.24, and 0.22 in Sichuan, respectively. RMSE in Hebei is lower than in Sichuan. The value of EF in Sichuan is closer to 1 than in Hebei. Moreover, the relative error, E, in Sichuan is lower and closer to 0 than in Hebei, which reflects the better simulation efficiency in Sichuan. 

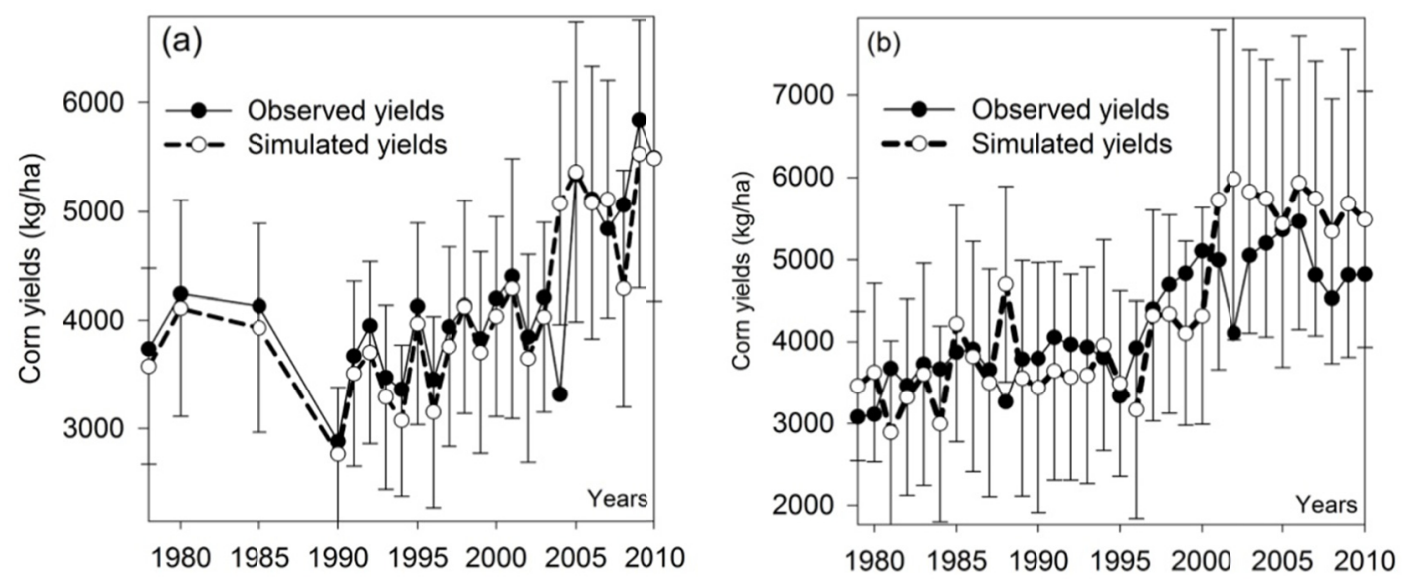

Figure 5. Mean observed and simulated corn yields in the province of (a) Hebei and (b) Sichuan. The bars represent plus and minus one standard deviation for simulated value

Figure 6 presents the variation of six meteorological variables $\left(\mathrm{T}_{\max }, \mathrm{T}_{\min }\right.$, Dswrf, $\mathrm{RH}$, Wind, and Prcp) over the past 33 years (1978-2010) in these two provinces. $\mathrm{T}_{\max }$ and $\mathrm{T}_{\min }$ increased at a rate of $0.22{ }^{\circ} \mathrm{C} / 10 \mathrm{yr}$ and $0.23{ }^{\circ} \mathrm{C} / 10 \mathrm{yr}$ (the method: estimation of linear trend (Fu et al., 2013) in Sichuan, respectively, and $0.34{ }^{\circ} \mathrm{C} / 10 \mathrm{yr}$ and $0.55^{\circ} \mathrm{C} / 10 \mathrm{yr}$ in Hebei, respectively).

Downward shortwave radiation (Dswrf) increased at a rate of 1.92 (langleys/day)/10 yr in Sichuan, and decreased at a rate of -0.82 (langleys/day) $/ 10 \mathrm{yr}$ in Hebei. $\mathrm{RH}$ decreased at a rate of $-0.06 \% / 10 \mathrm{yr}$ in Sichuan, and increased at a rate of $-0.45 \% / 10 \mathrm{yr}$ in Hebei. Wind decreased at a rate of -0.11 (miles/hour) $/ 10 \mathrm{yr}$ in Sichuan, and increased at a rate of 0.08 (miles/hour) $/ 10 \mathrm{yr}$ in Hebei. Precipitation decreased at a rate of $-0.01 \mathrm{~cm} / 10 \mathrm{yr}$ in both Sichuan and Hebei. The $Z$ values (the method: Mann-Kendall nonparametric statistical test (Kahya \& Kalayci, 2004) of the change in six meteorological variables were all more than $1.78(\alpha<0.05)$, indicating significant change trends of six climatic factors over the past 33 years.

To elucidate how each of the climatic factors affected corn yield, we analyzed the relations of six meteorological variables averaged over the growing season (April-September) from 1948-2010 with observed and simulated corn yields. Table 1 shows the correlation coefficients. In general, simulated and observed correlations are consistent with each other. However, in a few cases, the observations show significant results that were not confirmed by the simulations. In Hebei province, RH and Prcp exhibited a significant negative correlation with observed crop yields in the growing season. This is likely because the continuous rainfall in the pollination period seriously impacted the growth of maize (Liu, 2008). In Sichuan province, only $T_{\min }$ was negatively correlated with observed crop yields. There was no impact for $\mathrm{T}_{\max }$ on observed corn yield in Sichuan. This is probably because the mean air temperature in Sichuan is relatively high, which usually met the needs of corn growth. The rising of $\mathrm{T}_{\min }$ in Sichuan could cause the seeding time and the end of the growing season appear earlier and shorten the growing season of corn (Liu, Qin, Ge, Dai, \& Chen, 2017), thus decreasing corn production. 

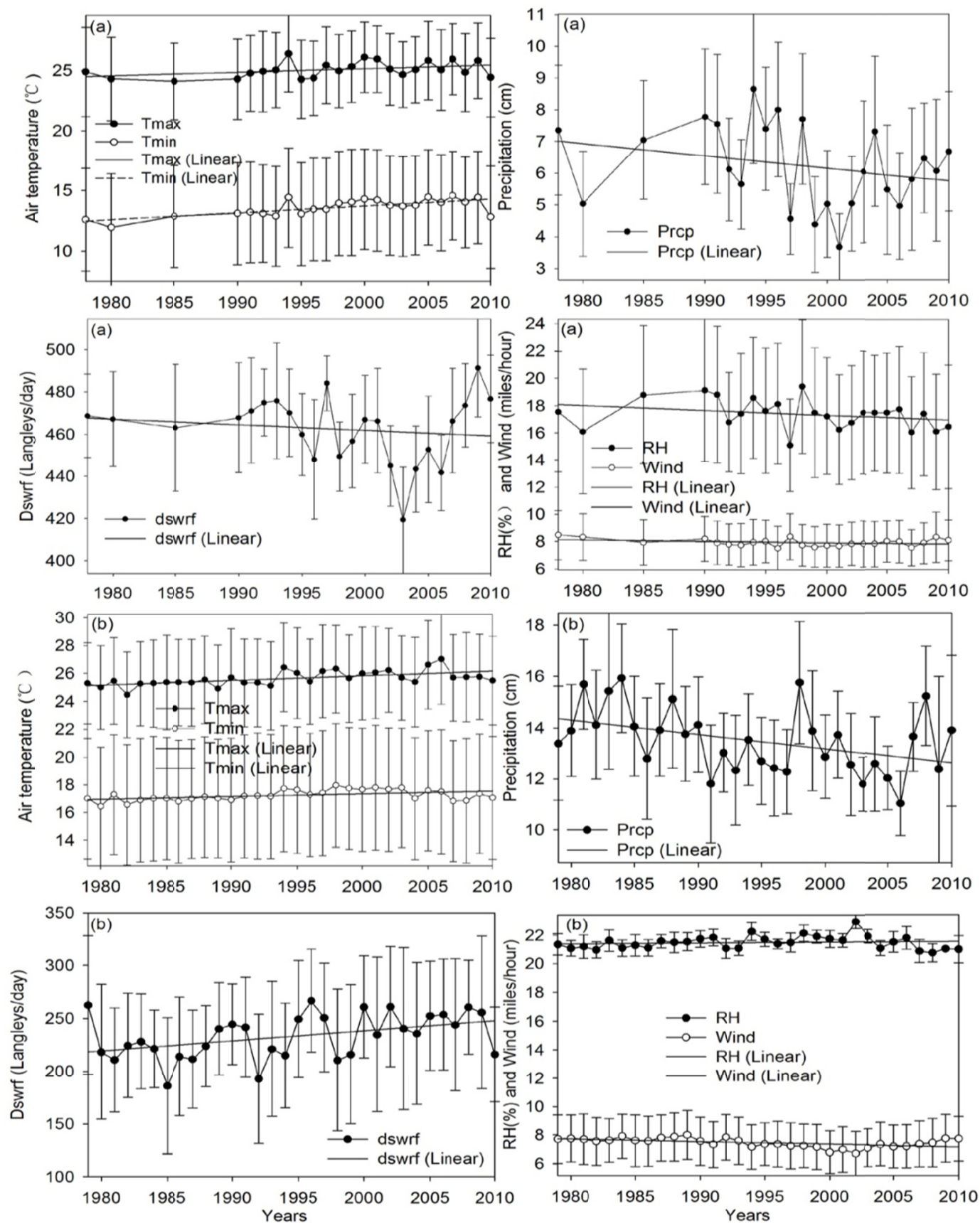

Figure 6. The annual change of six climatic factors (a) from 1978 to 2010 in Hebei and (b) from 1979 to 2010 in Sichuan. The bars represent plus and minus one standard deviation 
Table 1. Pearson correlation between the average values of six meteorological factors from April to September, and crop yields in 1978-2010 in Hebei and in 1979-2010 in Sichuan provinces

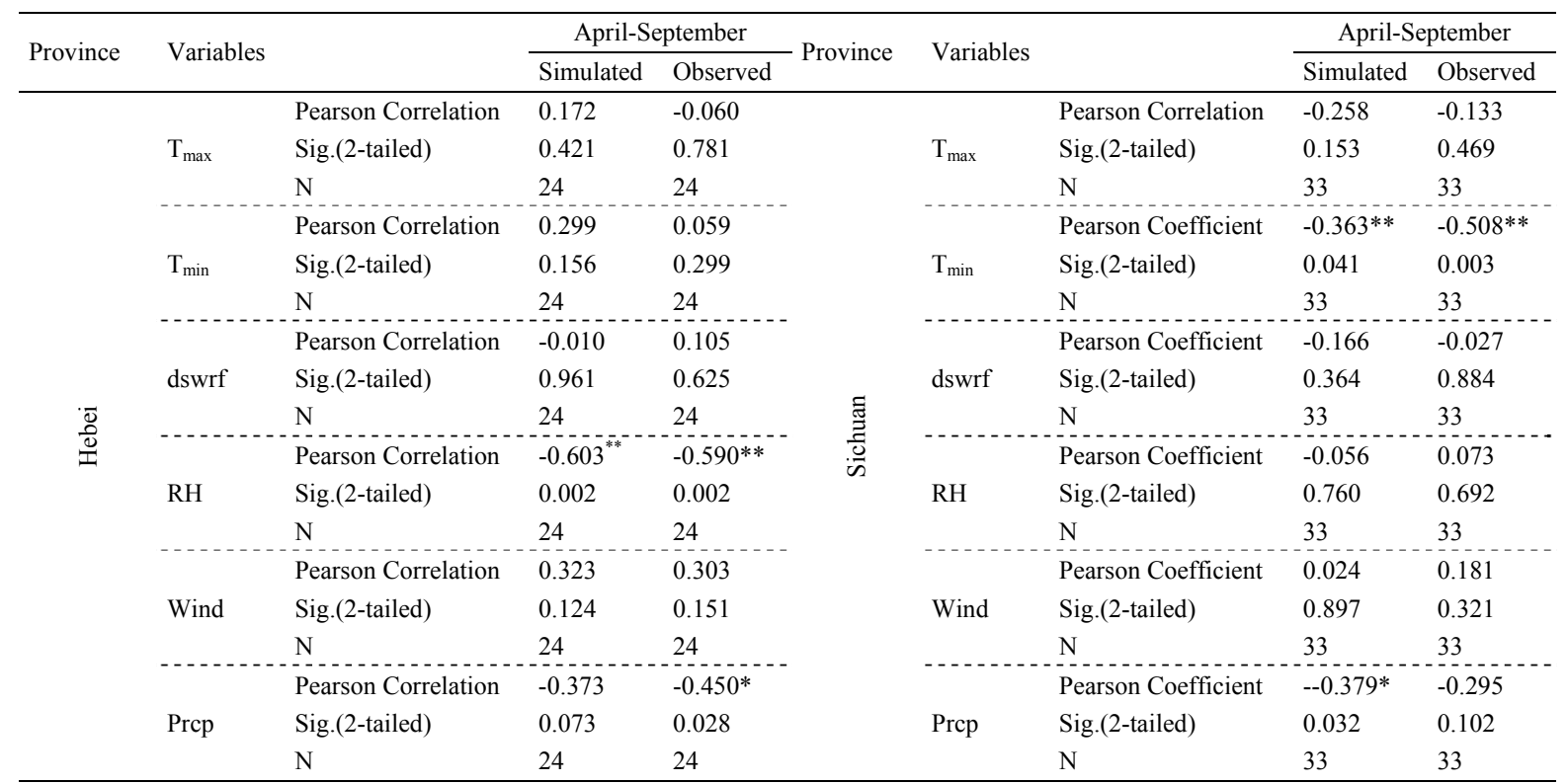

Note. ${ }^{*}$. Correlation is significant at the 0.05 level (2-tailed); **. Correlation is significant at the 0.01 level (2-tailed).

\subsection{Spatial Variations of Corn Yield Simulation}

The spatial distribution of simulated corn yields in 1948-2010 in Hebei revealed that corn yields in central and north Hebei were more than yields in the south (Figure 7a). Corn yields in Chengde, Baoding and Shijiazhuang were the greatest in the whole province, while corn yields in Tangshan, Hengshui, Langfang, and Xintai were the least. Corn yields in the entire province increased from 1948 to 2010. North of Zhangjiakou, yields increased from 1948 to 1999, but decreased substantially after 2000 compared to other regions. Additionally, corn yields in the north of Chengde decreased substantially compared to other regions from 1948 to 2010. Reduction of corn production that occurred after 2000 was observed in Zhangjiakou and Chengde, which could be due to continuous rainfall in the pollination period and drought in the grain formation-mature period (Liu, 2008; Zhang, 2014; Liu, 2013).

In Sichuan province (Figure 7b), high-yield corn is mainly located east of Sichuan, especially in the northeastern and southeastern regions of the province, which is associated with topographic features and agriculture distribution. Corn yields in Guangyuan, Bazhong, Deyang, Ziyang and Daxian were the greatest in the whole province, while those in Xiaojin, Yaan, and Mianning distributed in the central of Sichuan were the least. After 2000, corn yields in Bazhong, Daxian, Ziyang, Nanchong, Guangan, Yibin, Luzhou, Neijiang, and Zigong decreased substantially compared to other regions (Figure 8). Zhu and Yang (2007) found that corn yields have continued to decline since 2000 due to large-scale adjustment of planting areas of maize under the policy of returning farmland to forest in Sichuan. This simulated yield reflected the declination of corn yields, in agreement with Zhu and Yang (Zhu \& Yang, 2007). 


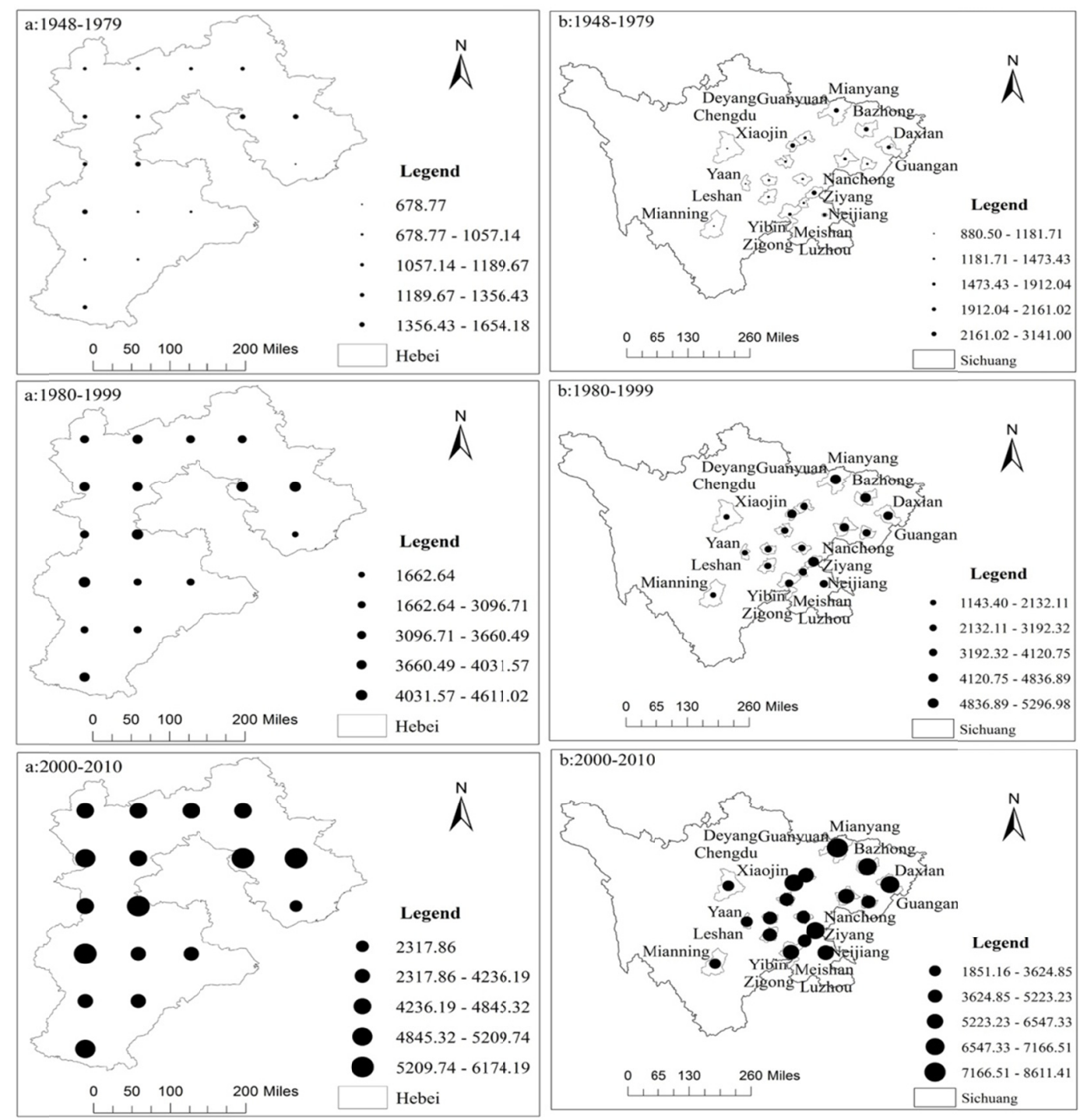

Figure 7. Spatial variations on simulated corn yields in 1948-1979, 1980-1999, and 2000-2010 in the province of (a) Hebei and (b) Sichuan

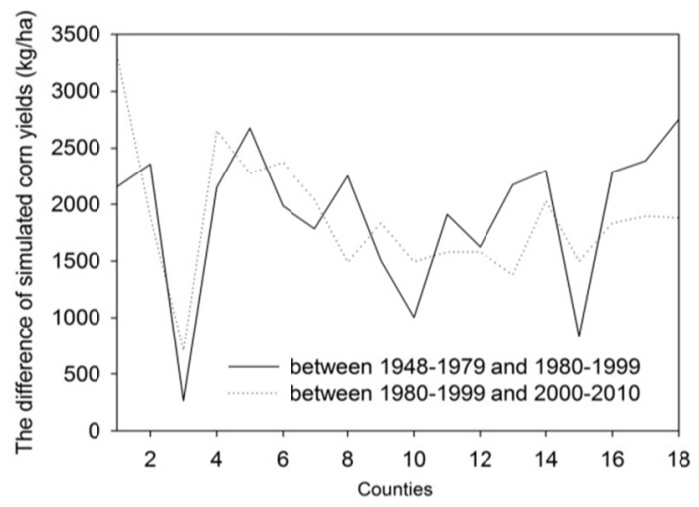

Figure 8. The differences of simulated corn yields between 1980-1999 and 1948-1979, and between 2000-2010 and 1980-1999 in Sichuan. Thereinto, in horizontal ordinate, 1-18 represents Guangyuan, Bazhong, Xiaojin, Mianyang, Daxian, Deyang, Chengdu, Guangan, Meishan, Yaan, Ziyang, Leshan, Zigong, Yibin, Mianning, Luzhou, Neijiang and Nanchong, respectively 


\subsection{Impact of Regional Warming on Corn Yield}

To test the regional warming effect, we removed the daily air temperature warming trend of the forcing meteorological data from 1978 to 2010 in the experiment. Figure 9 shows that, the variations of simulated corn yields with regional warming compared to those without regional warming were different during various phases of 1978-2010. In Hebei province, the annual mean corn yield in the controlled experiment after de-trending was $3794 \mathrm{~kg} / \mathrm{ha}$ in $1978-2003,4590 \mathrm{~kg} / \mathrm{ha}$ in $2004-2007$ and $5385 \mathrm{~kg} / \mathrm{ha}$ in $2008-2010$. Compared to the original simulated annual mean corn yields of $3684 \mathrm{~kg} / \mathrm{ha}$ in $1978-2003,5156 \mathrm{~kg} / \mathrm{ha}$ in $2004-2007$ and $5097 \mathrm{~kg} / \mathrm{ha}$ in $2008-2010$, mean corn yields increased by $110 \mathrm{~kg} / \mathrm{ha}$ in $1978-2003$ and $288 \mathrm{~kg} / \mathrm{ha}$ in $2008-2010$, respectively, decreased by $565 \mathrm{~kg} / \mathrm{ha}$ in 2004-2007, with removing the warming trend. The change of mean simulated corn yields in Hebei was not significant $(Z=0.0095, \alpha>0.05$, resulting from Mann-Kendall test (Fu et al., 2013)).
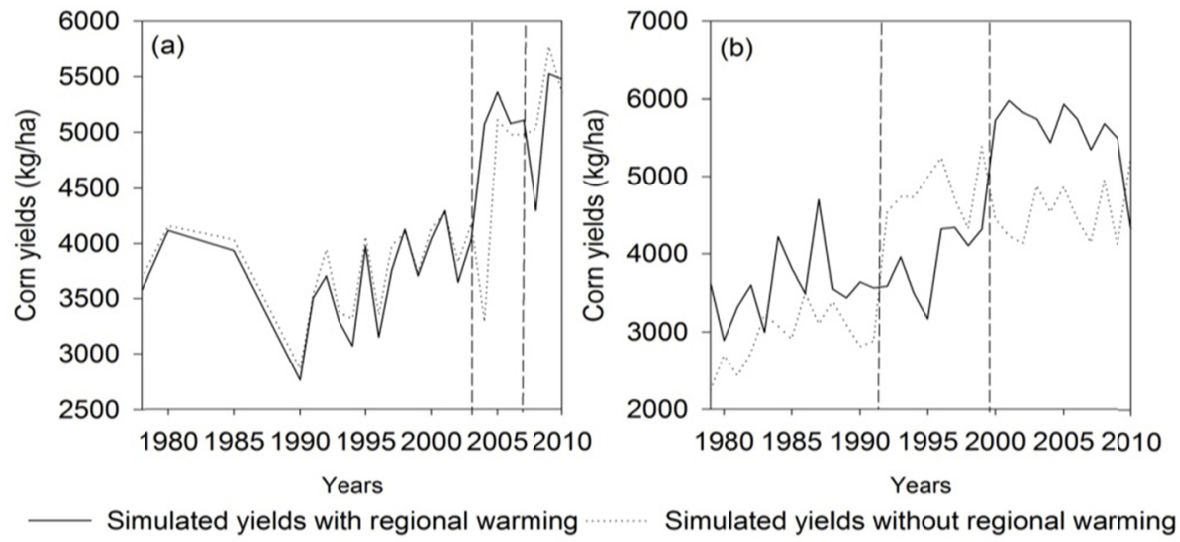

Figure 9. Changes of corn yields with/without regional warming in the province of (a) Hebei and (b) Sichuan

In Sichuan, the simulated mean corn yields before and after de-trending were $3604 \mathrm{~kg} / \mathrm{ha} / \mathrm{yr}$ and $2931 \mathrm{~kg} / \mathrm{ha} / \mathrm{yr}$ in $1979-1991,3909 \mathrm{~kg} / \mathrm{ha} / \mathrm{yr}$ and $4832 \mathrm{~kg} / \mathrm{ha} / \mathrm{yr}$ in $1992-1999,5567 \mathrm{~kg} / \mathrm{ha} / \mathrm{yr}$ and $4540 \mathrm{~kg} / \mathrm{ha} / \mathrm{yr}$ in $2000-2010$ respectively, which shows that rising air temperature enhanced corn yields in 1979-1991 and 2000-2010, increasing them by $674 \mathrm{~kg} / \mathrm{ha} / \mathrm{yr}$ and $1027 \mathrm{~kg} / \mathrm{ha} / \mathrm{yr}$ on average in these two periods, affected corn growth in $1992-1999$, decreasing them by $923 \mathrm{~kg} / \mathrm{ha} / \mathrm{yr}$. These change were significant $(Z=1.53, \alpha<0.05)$. The reason why rising air temperature has a significant impact on corn yields in Sichuan is that the warming of air temperature extends the summer and increased solar radiation, which allows to plant spring corn, summer corn and silage corn in more regions in a year under the condition of enough precipitation (Figure 6) in 1979-1991 and 2000-2010, so corn yields were increased. In the 1990s, precipitation was the least compared to other periods in Sichuan (Zhou et al., 2011). Therefore, the drought degree intensified in the 1990s in Sichuan with the rising of air temperature and the decrease of precipitation (Figure 6), which led to the reduction of corn yields. However, in Hebei, the warming of air temperature intensified drought and increased evapotranspiration. Sufficient irrigation can compensate for the need of more water in corn growth. Therefore, the rising air temperature did not lead to the significantchange of corn yield in Hebei.

From this, we can see that the sensitivity of simulated corn yields to elevated air temperature was greater in hot and humid environments than in cold and dry environments. In contrast, Liu (2008) reported that the adaptation of crops to the warming of air temperature was low, revealing the inhibition effect on yield in a warm province, and founding that area growth and development of crops were accelerated, but the growth period was shortened, and total dry weight was reduced with rising air temperature. The results in this paper were not controversial to that reported by Liu (Liu, 2008). The increase of corn yields with the rising air temperature is mainly because the enlargement of two bifurcation corn plant area in Sichuan, especially silage corn in large quantities (Duan, 2014). The negative correlation between $\mathrm{T}_{\min }$ and corn yields (Table 1) also showed that the negative impact of air temperature warming on corn yields, which is in agreement with the report by Liu (Liu, 2008).

The variation of simulated corn yields among different mean growing season air temperature in 1978-2010 in Hebei and in 1979-2010 in Sichuan were calculated and analyzed using the least significant difference (LSD) by SPSS 13.0 software (Table 2). The annual mean growing season air temperature in 1978-2010 in Hebei and in 1979-2010 in Sichuan are taken as control factors, and simulated annual corn yields as the dependent variables. After the control factors were sorted in ascending order, and the dependent variables were correspondingly 
sorted with the control factors, the control factors in the different provinces were divided into three levels from small to large, respectively (Table 2). Then, the significance of the difference between the dependent variables among these three levels of the control factors was analyzed using the LSD method. The results showed that, in Hebei, when the mean growing season air temperature increased from $18.69{ }^{\circ} \mathrm{C}$ to $19.41{ }^{\circ} \mathrm{C}$, and then to $20.21{ }^{\circ} \mathrm{C}$, there was no significant difference between simulated corn yields, which indicates that there was not a critical threshold value of air temperature influencing corn yields when the growing season air temperature varied in the range of $18.69^{\circ} \mathrm{C}-20.21^{\circ} \mathrm{C}$. In Sichuan, when the air temperature rose from $22.29{ }^{\circ} \mathrm{C}$ to $22.68{ }^{\circ} \mathrm{C}$, simulated corn yields varied non-significantly, but at $23.33^{\circ} \mathrm{C}$, simulated corn yields changed significantly, which shows that $23.33{ }^{\circ} \mathrm{C}$ may constitute a critical threshold value influencing simulated corn yields. The change in the growing season air temperature was positively associated with simulated corn yields with the correlation coefficient of 0.456 (sig. $=0.009<0.05$ ) (Table 3). Therefore, when the mean growing season air temperature was over $23.33^{\circ} \mathrm{C}$, simulated corn yields increased with the rising of air temperature in Sichuan province. Wolfram and Michael (2009) also found that annual mean air temperature affects corn yields. They indicated that crop yield would increase with elevated air temperature up to $29{ }^{\circ} \mathrm{C}$. Moreover, above this threshold value of air temperature, further warming would have a detrimental effect on yield. The results of this study are not contradictory to those of Wolfram and Michael (2009), and provide a minimum value of air temperature influencing and increasing corn yields. The annual mean air temperature in the growing season of corn (April to September) in Sichuan and Hebei are $22.83{ }^{\circ} \mathrm{C}$ and $19.34{ }^{\circ} \mathrm{C}$, respectively. Therefore, when the mean growing season air temperature reaches $23.33{ }^{\circ} \mathrm{C}-29^{\circ} \mathrm{C}$ in Sichuan, corn yields increase with the rising air temperature. It has been found that the 1990s are the warmest 10 years in 1948-2010 because the number of days over $29^{\circ} \mathrm{C}$ of actual air temperature in the growing season was more than 190 days in each year of seven years of 1990s. This long period and continuous high temperature are also probably the factors leading to the reduction of corn yields in the 1990s.

Table 2. The least significant difference (LSD) analysis on simulated corn yields among the different growing season air temperature levels in Hebei and Sichuan provinces

\begin{tabular}{|c|c|c|c|c|c|}
\hline Provinces & Air temperature $(\mathrm{I})\left({ }^{\circ} \mathrm{C}\right)$ & Air temperature (II) $\left({ }^{\circ} \mathrm{C}\right)$ & Mean difference (I-J) & Std. Error $\left({ }^{\circ} \mathrm{C}\right)$ & Significance \\
\hline \multirow{6}{*}{ Hebei } & \multirow{2}{*}{18.69} & 19.41 & $998.71 *$ & 464.27 & 0.043 \\
\hline & & 20.21 & 120.71 & 439.25 & 0.786 \\
\hline & \multirow{2}{*}{19.41} & 18.69 & $-998.71 *$ & 464.27 & 0.043 \\
\hline & & 20.21 & $-878.00 * *$ & 308.16 & 0.010 \\
\hline & \multirow{2}{*}{20.21} & 18.69 & -120.71 & 439.15 & 0.786 \\
\hline & & 19.41 & $878.00 * *$ & 308.16 & 0.010 \\
\hline \multirow{6}{*}{ Sichuan } & \multirow{2}{*}{22.29} & 22.68 & $-1046.71 * *$ & 323.42 & 0.003 \\
\hline & & 23.33 & $-1442.88 * *$ & 526.99 & 0.010 \\
\hline & \multirow{2}{*}{22.68} & 22.29 & $1046.71 * *$ & 323.42 & 0.003 \\
\hline & & 23.33 & -396.16 & 550.43 & 0.477 \\
\hline & \multirow{2}{*}{23.33} & 22.29 & $1442.88 * *$ & 526.99 & 0.010 \\
\hline & & 22.68 & 396.16 & 550.43 & 0.477 \\
\hline
\end{tabular}

Note. *. LSD is significant at the 0.05 level (2-tailed); **. LSD is significant at the 0.01 level (2-tailed).

Table 3. Pearson correlation coefficients between the mean growing season air temperature and simulated corn yields in Hebei and Sichuan provinces

\begin{tabular}{lll}
\hline Provinces & Correlation coefficients & Significance (2-tailed) \\
\hline Hebei & 0.294 & 0.163 \\
Sichuan & $0.456^{* *}$ & 0.009 \\
\hline
\end{tabular}

\subsection{Sensitivity Analysis}

Anandhi (2016) also analyzed the impact of management decisions, such as plant water use, fertilizer application and hybrids on corn yields, and found inadequate $\mathrm{N}$ fertility results in lower yields, whereas over-fertilization results in higher emissions of nitrous oxide. Here, we examine the changes in yields that result from increasing or decreasing inorganic and organic $\mathrm{N}$ applications. 


\subsubsection{Sensitivity to Inorganic N Fertilization Levels}

The original fertilization levels (Table 4) were increased or decreased by $50 \%$ and $75 \%$ without changing other factors. In Hebei province, when the fertilization level was increased by $50 \%$ and $75 \%$, mean annual yields from 1979 to 2010 increased by $2136 \mathrm{~kg} / \mathrm{ha}(52 \%)$ and $2448 \mathrm{~kg} / \mathrm{ha}(59 \%)$, respectively; when the fertilizer level was decreased by $50 \%$ and $75 \%$, mean annual yields decreased by $2130 \mathrm{~kg} / \mathrm{ha}(52 \%)$ and $3095 \mathrm{~kg} / \mathrm{ha}(75 \%)$, respectively (Figure 10a). In Sichuan province, the mean annual yields from 1978 to 2010 were higher by 1467 $\mathrm{kg} / \mathrm{ha}(34 \%)$ and $2346 \mathrm{~kg} / \mathrm{ha}(55 \%)$ after a $50 \%$ and $75 \%$ increase in fertilization level, respectively; yields were lower by $2354 \mathrm{~kg} / \mathrm{ha}(55 \%)$ and $3369 \mathrm{~kg} / \mathrm{ha}(78 \%)$, respectively, when the fertilization level decreased by $50 \%$ and $75 \%$ (Figure 10b). Fertilization level increases in a cold and dry environment (in Hebei) were more beneficial than in a humid and hot environment (in Sichuan) in terms of percentage change. However, when the fertilization levels were decreased, crop yield in Sichuan suffered more than in Hebei. These results indicated that the sensitivity of the fertilization level influencing corn yield simulation was great in these two provinces. This is probably associated with the original soil fertility condition. It has been reported that the soil in Sichuan was more fertile than that in Hebei because of the humid and hot environment in Sichuan (Zhang, 2014), and because of the higher $\mathrm{N}$ fertilization level in Sichuan than that in Hebei (Table 4). In addition, corn yields in Hebei increased slightly with the mean increase amount of $312 \mathrm{~kg} / \mathrm{ha} / \mathrm{yr}$ when the fertilization levels increased from $50 \%$ to $75 \%$, which was less than the mean increase amount of $879 \mathrm{~kg} / \mathrm{ha} / \mathrm{yr}$ in Sichuan (Figure 10). This demonstrates that crop yield increases are not proportional to $\mathrm{N}$ fertilizer increases, and that fertilizer addition above $+50 \%$ produces diminishing returns (Zhang, 2014; Luo, 2009).
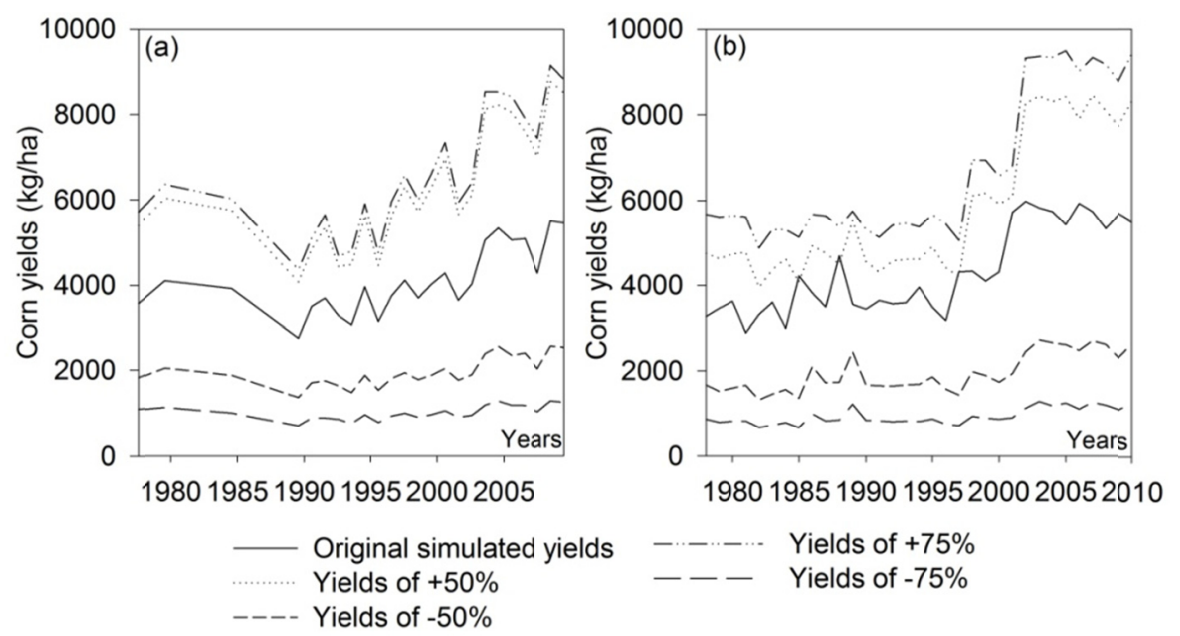

Figure 10. Changes on original simulated corn yields and yields of the control experiment when adding and extracting $50 \%$ and $75 \%$ of fertilization in the province of (a) Hebei and (b) Sichuan
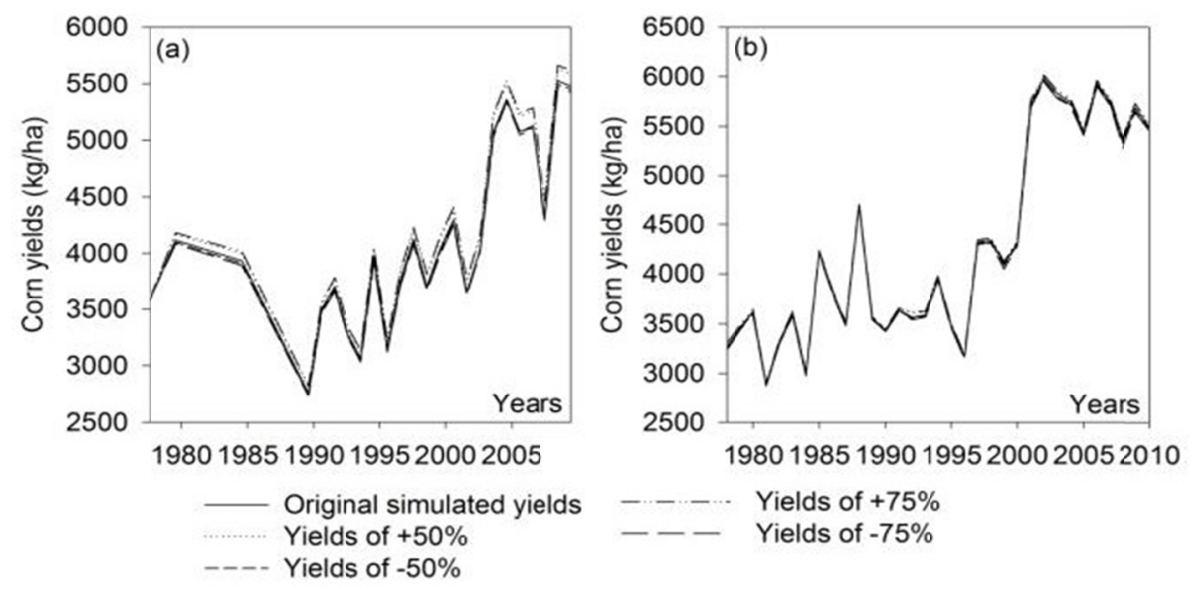

Figure 11. Changes on original simulated corn yields and yields of the control experiment when adding and extracting $50 \%$ and $75 \%$ of OMAD in the province of (a) Hebei and (b) Sichuan 
Table 4. $\mathrm{N}$ fertilization levels and OMAD in the control run

\begin{tabular}{lllll}
\hline Provinces & Phrases set in schedule file & $\begin{array}{l}\text { N fertilization level I } \\
(\mathrm{kg} \mathrm{N} / \mathrm{ha} / \mathrm{yr})\end{array}$ & $\begin{array}{l}\mathrm{N} \text { fertilization level II } \\
(\mathrm{kg} \mathrm{N} / \mathrm{ha} / \mathrm{yr})\end{array}$ & $\begin{array}{l}\text { Organic C } \\
(\mathrm{kg} \mathrm{C} / \mathrm{ha} / \mathrm{yr})\end{array}$ \\
\hline \multirow{3}{*}{ Sichuan } & $1701-1900$ & 60 & 60.5 & 23.1 \\
& $1901-1960$ & 60 & 60.5 & 23.1 \\
& $1961-1970$ & 93 & 94 & 57.7 \\
& $1971-1980$ & 112 & 117 & 69.0 \\
& $1981-1996$ & 117 & 118 & 81.0 \\
& $1997-2000$ & 142 & 146 & 92.0 \\
& $2001-2010$ & 142 & 146 & 92.0 \\
\hline \multirow{3}{*}{ Hebei } & $1701-1900$ & 18.6 & 18.6 & 23.1 \\
& $1901-1960$ & 18.6 & 18.6 & 23.1 \\
& $1961-1976$ & 60.5 & 63 & 46.1 \\
& $1977-1996$ & 66 & 66.9 & 57.7 \\
& $1997-2002$ & 66.9 & 67 & 57.7 \\
\hline
\end{tabular}

\subsubsection{Sensitivity to OMAD}

After corn is harvested each year, soil fertility needs to be replenished to benefit corn growth in the following year. The amount of organic $\mathrm{N}$ that was applied in the control runs was $20 \mathrm{~kg} / \mathrm{ha} / \mathrm{yr}$. The $\mathrm{C}: \mathrm{N}$ ratio of the organic matter applied was 15 . We conducted sensitivity studies by adding or decreasing $50 \%$ and $75 \%$ of the original OMAD level. There was no difference in the mean control and experimental simulations yields in 1979-2010 in Sichuan (Figure 11b); whereas, there was a slight increase in 1978-2010 mean yields $(59.05 \mathrm{~kg} / \mathrm{ha} / \mathrm{yr})$ in Hebei (Figure 11a). This is also probably related to the original soil fertilization condition. The higher inorganic $\mathrm{N}$ soil fertilization amounts in Sichuan meet the needs of corn growth. There was no need for additional organic N fertilizer in the field. In addition, the reason that OMAD increases are not important to either province is probably different. In Hebei, when corn is harvested in autumn, OMAD cannot efficiently improve soil fertility for drier soil; in Sichuan, OMAD can improve soil fertility for humid soil due to ample precipitation and irrigation.

Generally, fertilization level and OMAD have a larger impact in Hebei (cold and dry environment), where there is less active biophysical activity due to lower soil moisture and warmth. Increased soil fertilization can improve soil biophysical activities and meet the needs of corn growth (Tan et al., 2002).

\section{Conclusions}

The DayCent model is used to simulate corn yields under different environmental conditions in China. The model reproduced the inter-annual variation of crop yield with a $\mathrm{R}^{2}$ of 0.71 and 0.85 in Hebei and Sichuan, China, respectively, demonstrating that the DayCent model is capable of accurately simulating corn yield in these two environments.

The annual mean $\mathrm{T}_{\max }$ and $\mathrm{T}_{\min }$ increased at a rate of $0.22{ }^{\circ} \mathrm{C} / 10 \mathrm{yr}$ and $0.23{ }^{\circ} \mathrm{C} / 10 \mathrm{yr}$ in Sichuan, respectively, and $0.34{ }^{\circ} \mathrm{C} / 10 \mathrm{yr}$ and $0.55^{\circ} \mathrm{C} / 10 \mathrm{yr}$ in Hebei, respectively. The annual mean downward shortwave radiation (Dswrf) increased at a rate of 1.92 (langleys/day)/10 yr in Sichuan, and decreased at a rate of -0.82 (langleys/day)/10 yr in Hebei. The annual mean RH decreased at a rate of $-0.06 \% / 10 \mathrm{yr}$ in Sichuan, and increased at a rate of $-0.45 \% / 10 \mathrm{yr}$ in Hebei. The annual mean wind decreased at a rate of -0.11 (miles/hour) $/ 10$ $\mathrm{yr}$ in Sichuan, and increased at a rate of 0.08 (miles/hour)/10 yr in Hebei. The annual mean precipitation decreased at a rate of $-0.01 \mathrm{~cm} / 10 \mathrm{yr}$ in both Sichuan and Hebei.

In this paper, the impacts of climatic factors and management amendment levels on corn yields were explored. The results showed that RH and Prcp negatively affected corn yields in Hebei (a cold and dry environment). That impacts of the rising of $T_{\max }$ and $T_{\min }$ on corn yields were not significant is because corn growth in Hebei mainly depends on irrigation, and is not constrained by the drought resulting from the rising air temperature. Only $\mathrm{T}_{\min }$ negatively affected corn yields in Sichuan.

Simulated corn yields decreased significantly after de-trending the warm air temperature in Sichuan. There was no critical threshold value of air temperature influencing corn yield simulation in Hebei; whereas, $23.33{ }^{\circ} \mathrm{C}$ was the critical threshold value influencing simulated corn yields in Sichuan. 
The sensitivity study suggests that crop yield is more sensitive to fertilization level in a cold and dry environment as compared to that in a humid and hot environment. Fertilizer application can remedy the shortage of soil fertility, and accelerate crop growth in a cold and dry environment.

In Sichuan province (a humid and hot environment), current air temperature is limiting to corn production. $23.33{ }^{\circ} \mathrm{C}-9{ }^{\circ} \mathrm{C}$ constitutes the ideal scale of air temperature influencing increase of corn yields.

\section{Acknowledgements}

This study was financially supported by the Thousand Talent Program for Young Outstanding Scientists of China (No. Y971071) and the U.S. NSF Grant AGS-1419526. We appreciate the help of Dr. William J. Parton of the Colorado State University in this research.

\section{References}

Almarza, J. J., Mabood, F., Zhou, X. M., Gregorich, E. G., \& Smith, D. L. (2008). Climate change, weather variability and corn yield at a higher latitude locale: Southwestern Quebec. Climatic Change, 88, 187-197. https://doi.org/10.1007/s10584-008-9408-y

Anandhi, A. (2016). Growing degree days-Ecosystem indicator for changing diurnal temperatures and their impact on corn growth stages in Kansas. Ecol Indic, 61, 149-158. https://doi.org/10.1016/ j.ecolind.2015.08.023

Basche, A. D., Archontoulis, S. V., Kaspar, T. C., Jaynes, D. B., Parkin, T. B., \& Miguez, F. E. (2016). Simulating long-term impacts of cover crops and climate change on crop production and environmental outcomes in the Midwestern United States. Agric Ecosyst Environ, 218, 95-106. https://doi.org/10.1016/ j.agee.2015.11.011

Bryan, B. A., King, D., \& Zhao, G. (2014). Influence of management and environment on Australian wheat: Information for sustainable intensification and closing yield gaps. Environ Res Lett, 9(4), 044005. https://doi.org/10.1088/1748-9326/9/4/044005

Campbell, E. E., Johnson, J. M. E., Jin, V. L., Lehman, R. M., Osborne, S. L., Varvel, G. E., \& Paustian, K. (2014). Assessing the soil carbon, biomass production, and Nitrous Oxide emission impact of corn stover management for bioenergy feedstock production using DAYCENTDAYCENT. Bioenergy Res, 7, 491-502. https://doi.org/10.1007/s12155-014-9414-z

Chen, B., \& Chen, G. (2007). Resource analysis of the Chinese society 1980-2002 based on exergy-Part 3: Agricultural products. Energy Policy, 35(4), 2065-2078. https://doi.org/10.1016/j.enpol.2006.07.007

Chen, S., Chen, X. G., \& Xu, J. T. (2016). Impacts of climate change on agriculture: Evidence from China. $J$ Environ Econ Manage, 76, 105-124.

Chen, T. K. (2013). Cultivation techniques of corn in heat preservation, water saving and high yield in middle mountain hilly area. Agric Farm Mchnr Sichuan, 4, 39.

Cheng, K., Ogle, S. M., Parton, W. J., \& Pan, G. X. (2014). Simulating greenhouse gas mitigation potential for Chinese croplands using the DAYCENT ecosystem model. Glob Change Biol, 20, 948-962. https://doi.org/ $10.1111 / \mathrm{gcb} .12368$

Duan, T. (2014). Problems and countermeasures on the development of new forage industry in Sichuan Hongya (M. Sc. Thesis, Sichuan Agricultural University, China). Retrieved from http://www.doc88.com/p-66612 58710137.html

Frey, S. D., Lee, J. W., Melillo, J. M., \& Six, J. (2015). The temperature response of soil microbial efficiency and its feedback to climate. Nature Climate Change, 3, 395-398. https://doi.org/10.1038/nclimate 1796

Fu, A. H., Chen, Y. N., Li, W. H., Li, B. F., Yang, Y. H., \& Zhang, S. H. (2013). Spatial and temporal patterns of climate variations in the Kaidu River Basin of Xinjiang, Northwest China. Quat Int, 311, 117-122. https://doi.org/10.1016/j.quaint.2013.08.041

Janssen, P. H. M., \& Heuberger, P. S. C. (1995). Calibration of process oriented models. Ecol Modell, 83, 55-66. https://doi.org/10.1016/0304-3800(95)00084-9

Kahya, E., \& Kalayci, S. (2004). Trend analysis of streamflow in Turkey. J Hydrol, 289, 128-144. https://doi.org/10.1016/j.jhydrol.2003.11.006

Lee, J. W., De, G. S., \& Six, J. (2011). Effect of climate change on field crop production in California's Central Valley. Climatic Change, 109(Suppl. 1), S335-S353. https://doi.org/10.1007/s10584-011-0305-4 
Lee, J., \& Durmaz, N. (2016). Impact of climate change on corn production in the U.S.: Evidence form panel study. Appl Econom Intl Development, 16(1), 93-104.

Liang, M. Y. (2015). A systematic analysis on nitrogen balance of wheat-maize cropping system in the Hebei Plain (M. Sc. Thesis, Hebei Agricultural University, China).

Liang, W. L., Lv, H. Z., Wang, G. Y., Xia, A. P., Lv, R. H., \& Qin, F. S. (2008). Potential productivity, limiting factors and development approaches of cropping system on wheat-maize in Hebei Plain. Res Progress Agri Syst Chin, 160-168.

Liu, H. Q. (2013). Regional climate variability and its influence on hydrology and water resources in Yongding River Basin of Zhangjiakou (Doctoral Dissertation, Hebei Agricultural University, China). Retrieved from http://www.doc88.com/p-0127228826246.html

Liu, Y. H., Yang, Y. M., He, G. Y., Li, B. G., Wu, G. Q., \& Zeng. W. K. (1998). A study on the suitable planting regions in Sichuan for several maize varieties. Southwest Chin J Agric Sci, 11, 217-222.

Liu, Y. J. (2008). Analysis on regional impact of climate change on grain yield, China-A case study of corn (Doctoral Dissertation, Capital Normal University, China). Retrieved from http://www.doc88.com/ p-3867915643066.html

Liu, Y. J., Qin, Y., Ge, Q. S., Dai, J. H., \& Chen, Q. M. (2017). Responses and sensitivities of maize phenology to climate change from 1981 to 2009 in Henan Province, China. J Geogr Sci, 27(9), 1072-1084. https://doi.org/10.1007/s11442-017-1422-4

Lobell, D. B., \& Field, C. B. (2007). Global scale climate-crop yield relationships and the impacts of recent warming. Environ Res Lett, 2(1), 1-7. https://doi.org/10.1088/1748-9326/2/1/014002

Luo, J. M., Jin, G. H., Luo, Z. P., Wang, H. Y., Qi, Y. Q., Liu, X. R., \& Shen, Y. J. (2016). Production state and yield potential of wheat and maize in low-medium yield farmlands in Hebei Plain. Chin J Eco-Agric, 24(8), 1123-1134.

Luo, R. (2009). Soil nutrient contents and its varing tendency in cropland Sichuan province (M. Sc. Thesis, Sichuan Agricultural University, China). Retrieved from http://www.doc88.com/p-7854217095214.html

Mangalassery, S., Sjogersten, S., Sparkes, D. L., Sturrock, C. J., Craigon, J., \& Mooney, S. J. (2014). To water extent can zero tillage lead to a reduction in greenhouse gas emissions from temperate soils? Sci Rep, 4, 4586. https://doi.org/10.1038/srep04586

Meng, T., Carew, R., Florkowski, W. J., \& Klepacka, A. M. (2016). Analyzing temperature and precipitation influences on yield distributions of Canola and Spring Wheat in Saskatchewan. Journal of Applied Meteorology and Climatology, 56(4), 897-913. https://doi.org/10.1175/JAMC-D-16-0258.1

Morell, F. J., Yang, H. S., Cassman, K. G., Wart, J. V., Elmore, R. W., Licht, M., ... Grassini, P. (2016). Can crop simulation models be used to predict local to regional maize yields and total production in the U.S. Corn Belt? Field Crops Res, 192, 1-12. https://doi.org/10.1016/j.fcr.2016.04.004

Nendel, C., Kersebaum, K. C., Mirschel, W., \& Wenkel, K. O. (2014). Testing farm management options as climate change adaptation strategies using the MONICA model. Eur J Agron, 52(0), 47-56. https://doi.org/ 10.1016/j.eja.2012.09.005

Parton, W. J., Hartman, M. D., Ojima, D. S., \& Schimel, D. S. (1998). DAYCENTDAYCENT: Its land surface submodel: description and testing. Glob Planet Change, 19, 35-48. https://doi.org/10.1016/S0921-8181 (98)00040-X

Parton, W. J., Holland, E. A., Del Grosso, S. J., Hartman, M. D., Martin, R. E., Mosier, A. R., ... Schimel, D. S. (2001). Generalized model for $\mathrm{NO}_{\mathrm{x}}$ and $\mathrm{N}_{2} \mathrm{O}$ emissions from soils. J Geophys Res, 106, 17403-17420. https://doi.org/10.1029/2001JD900101

Peng, S., Tang, Q., \& Zou, Y. (2009). Current status and challenges of rice production in China. Plant Prod Sci, 12(1), 3-8. https://doi.org/10.1626/pps.12.3

Rafique, R., Fienen, M. N., Parkin, T. B., \& Anex, R. P. (2013). Nitrous Oxide emissions from cropland: A procedure for calibrating the DaycentDayCent biogeochemical model using inverse modeling. Water Air Soil Pollut, 224, 1677. https://doi.org/10.1007/s11270-013-1677-z 
Reay, D. S., Davidson, E. A., Smith, K. A., Smith, P., Melillo, J. M., Dentener, F., \& Crutzen, P. J. (2012). Global agriculture and nitrous oxide emissions. Nature Climate Change, 2, 410-416. https://doi.org/ $10.1038 /$ nclimate 1458

Robertson, G. P., Grace, P. R., Izaurralde, R. C., Parton, W. P., \& Zhang, X. S. (2014). $\mathrm{CO}_{2}$ emissions from crop residue-derived biofuels. Nature Climate Change, 4, 933-934. https://doi.org/10.1038/nclimate2402

Sheehan, J. J., Adler, P. R., Del Grosso, S. J., Easter, M., Parton, W., Paustian, K., \& Williams, S. (2013). CO emissions from crop residue-derived biofuels. Nature Climate Change, 4, 932-933. https://doi.org/10.1038/ nclimate 2403

Sheffield, J., Goteti, G., \& Wood, E. F. (2006). Development of a 50-yr high-resolution global dataset of meteorological forcings for land surface modeling. J Climate, 19(3), 3088-3111. https://doi.org/10.1175/ JCLI3790.1

Silva, J. V., Reidsma, P., Laborte, A. G., \& van Ittersum, M. K. (2017). Explaining rice yields and yield gaps in Central Luzon, Philippines: An application of stochastic frontier analysis and crop modeling. Eur J Agron, 82, 223-241. https://doi.org/10.1016/j.eja.2016.06.017

Tan, G. B., Bian, S. F., Liu, W. R., Zheng, J. Y., Ma, H., Zhang, L. H., \& Feng, Y. C. (2002). Analysis on planting of corn about wide alternative narrow row with cultivation technique. J Maize Sci, 10(2), 80-83.

Voloudakis, D., Karamanos, A., Economou, G., Kalivas, D., Vahamidis, P., Kotoulas, V., ... Zerefos, C. (2015). Prediction of climate change impacts on cotton yields in Greece under eight climatic models using the AquaCrop crop simulation model and discriminant function analysis. Agric Water Manage, 147, 116-128. https://doi.org/10.1016/j.agwat.2014.07.028

Wang, R. Y., Bowling, L. C., \& Cherkauer, K. A. (2016). Estimation of the effects of climate variability on crop yields in the Midwest USA. Agric For Meteorol, 216, 141-156. https://doi.org/10.1016/j.agrformet. 2015.10.001

Wieder, W. R., Bonan, G. B., \& Allison, S. D. (2014). Global soil carbon projections are improved by modelling microbial processes. Nature Climate Change, 3, 909-912. https://doi.org/10.1038/nclimate1951

Wolfram, S., \& Michael, J. R. (2009). Nonlinear temperature effects indicate severe damages to U.S. crop yields under climate change. PNAS, 106(37), 15594-15598. https://doi.org/10.1073/pnas.0906865106

Yin, X. G., Jabloun, M., Olesen, J. E., Ozturk, I., Wang, M., \& Chen, F. (2016). Effects of climatic factors, drought risk and irrigation requirement on maize yield in the Northeast Farming Region of China. $J$ Agric Sci, 1-19. https://doi.org/10.1017/S0021859616000150

Yu, Y., Huang, Y., \& Zhang, W. (2012). Changes in rice yields in China since 1980 associated with cultivar improvement, climate and crop management. Field Crops Res, 136(0), 65-75. https://doi.org/10.1016/ j.fcr.2012.07.021

Zhang, P. (2014). Soil nutrient status and fertilizer recommendation for maize production in Hebei (M. Sc. Thesis, Hebei Agricultural University, China). Retrieved from http://xueshu.baidu.com/s?wd=paperuri\% 3A\%283061f7c77c7d435e3e968331ce153854\%29\&filter=sc_long_sign\&tn=SE_xueshusource_2kduw22v

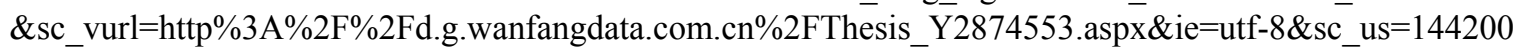
$384 \overline{7} 2690818338$

Zhao, R., Qu, Q. B., Feng, J., Zhi, S. L., Du, H. Y., \& Li, A. X. (2017). Developing tendency in animal husbandry in China and its control countermeasures over environmental pollution. Tianjin Agric Sci, 23(3), 9-16.

Zhou, C. Y., Cen, S. X., Li, Y. Q., Peng, G. Z., Yang, S. Q., \& Peng, J. (2011). Precipitation variation and its impacts in Sichuan in the last 50 years. Acta Geogr Sin, 66(5), 619-630.

Zhu, M. C., \& Yang, T. (2007). Analysis on current situation and characteristics of grain production in Sichuan province. Decision-making Consulting Communication, 7, 35-37.

\section{Copyrights}

Copyright for this article is retained by the author(s), with first publication rights granted to the journal.

This is an open-access article distributed under the terms and conditions of the Creative Commons Attribution license (http://creativecommons.org/licenses/by/4.0/). 